\title{
A INQUISIÇÃO DE PORTUGAL E A AMBIGUIDADE EM FACE AO CONHECIMENTO LETRADO NO OCASO DO ANTIGO REGIME
}

\author{
THE PORTUGUESE INQUISITION AND THE AMBIGUITY IN THE \\ FACE TO KNOWLEDGE ON ANCIENT REGIME
}

\author{
Igor Tadeu Camilo Rocha \\ Doutorando/UFMG \\ E-mail: igortcr@gmail.com
}

\begin{abstract}
Resumo:
Este artigo pretende analisar a atuação do Tribunal do Santo Ofício de Portugal durante no ocaso do século XVIII, tendo como objetivo verificar como se dava a relação entre este tribunal e o saber letrado dos acusados descritos nos processos, denúncias e apresentações. Numa primeira parte, pretende-se desenvolver um diálogo com a historiografia sobre a ilustração portuguesa, a fim de se discutir como que reformas conduzidas pelo Estado português contribuíram para a formação de sociabilidades ilustradas, nas quais se destacam os chamados libertinos. Num segundo momento, o objetivo é verificar a ambiguidade das percepções dos inquisidores em relação ao letramento desses mesmos libertinos. A esse saber letrado nota-se a atribuição de características positivas e negativas conforme determinadas relações construídas entre eles e formulações consideradas heréticas.
\end{abstract}

Palavras chave: Inquisição, cultura letrada, Libertinagem ${ }^{1}$.

\begin{abstract}
:
This article analyzes the role of the Court of Inquisition in Portugal at the twilight of the Old Regime, having carried out to verify how was the relationship between this courtand and the scholarly of the the accused described in the processes, reports and presentations. In the first part, will try to develop a dialogue with the historiography of the Portuguese illustration, in order to discuss how to reform instituted by the Portuguese state contributed to the formation of an illustrated sociability, in which we highlight the called libertines. Secondly, we will try to verify the ambiguity of perceptions of the inquisitors in relation to literacy of those
\end{abstract}

\footnotetext{
${ }^{1}$ Há de se fazer um parêntese acerca do termo libertino. Na atualidade, por exemplo, no famoso dicionário Aurélio, o primeiro significado que vem na sua definição é a de Livre de qualquer peia moral; devasso, dissoluto, depravado, licencioso. Ou seja, ganha um foco principal a caracterização de um indivíduo imoral e sexualmente dissoluto. No entanto, no final do Antigo Regime português, o termo tem significado distinto. Libertino, nesse contexto, segundo Luiz Carlos Villalta, assume uma acepção tripla. Primeiro, como livre pensador. No, libertino seria o indivíduo que não se curva ao dogma, não obedece a autoridades, que universaliza sua crítica, curvandose somente aos ditames da razão ilustrada. Nesse aspecto, ressaltam-se características como as da impiedade, irreligião, deísta, ateísta ou defensor do tolerantismo religioso. Um segundo aspecto, o de monarcômaco. No caso, que se opõe a todo tipo de tirania e supressão de liberdades. Nesse ponto, a definição ganha uma colocação política na medida em que em se difunde, entre as autoridades do Santo Ofício e Intendência Geral de Polícia a ideia de uma conspiração contra trono e altar empreendida por libertinos de seus locais de sociabilidade, por exemplo, as lojas maçônicas. O caráter licencioso e imoral em matéria de costumes e sexualidade surge como um aspecto que dialoga com ambos, já que a crítica moral contida nessa forma de comportamento é, por vezes, associada, tanto a crítica das verdades religiosas e ao dogma, como à dissolução moral que faria parte da corrupção e da imoralidade espalhada pelos libertinos através de seus folhetos, livros, romances, entre outros, afim de destruírem trono e altar (VILLALTA, 2012:78; BARATA,2006:31-80)
} 
libertines, where he would be assigned positive and negative characteristics as determined relationships built between them and his heretical formulations.

Keywords: Inquisition, lettered culture, licentiousness.

\section{Reformismo ilustrado e redefinição do papel do Santo Ofício em Portugal.}

Fundada em 1536, a Inquisição portuguesa tinha como objetivo a manutenção da ortodoxia moral, religiosa e política dos súditos do rei de Portugal. Foi uma instituição híbrida, já que ainda que tenha contado com tribunais eclesiásticos, nunca deixou de se afirmar como régio² (BETHENCOURT, 1993:153). Ao longo de seus quase três séculos de existência - de 1536 até 1821, com uma efêmera suspensão entre 1674 e 1681, por influência da Santa Sé de Roma e como resultado de disputas políticas internas (PAIVA, 2011: 157), embora com diversas alternâncias em seu funcionamento, a perseguição de judeus perpassou marcadamente a maior parte de sua história. O poder e a autoridade inquisitoriais, em Portugal, estiveram firmemente empenhados em denegrir e exterminar o judaísmo, assim como discriminar e explorar os cristãos novos (SCHWARTZ, 2009:168). Quando da sua implantação, não houve um grande período de terror inicial tal como ocorreu na Espanha ${ }^{3}$.

Houve um declínio gradual em relação à repressão dos judeus e cristãos novos ao longo de todo o século XVIII, acentuando-se essa tendência a partir de sua segunda metade (MARCOCCI e PAIVA, 2013: 359-366). Ela torna-se mais aguda no período que corresponde o Reformismo Ilustrado, recorte que abrange os reinados de D. José I (1750-

\footnotetext{
2 A Inquisição portuguesa afirma-se, segundo Francisco Bethencourt, com o duplo estatuto de tribunal eclesiástico e de tribunal da coroa. Eclesiástico por funcionar com poderes delegados pelo papa, além de ter por objetivo a perseguição das diversas formas de heresia, além de ter seus juízes, comissários e deputados como clérigos. Tipologias de desvios de fé por ela perseguidas (heresia, judaísmo, islamismo, sodomia, bigamia, blasfêmias, luteranismo, entre outros) encontram cobertura no direito canônico. Tribunal da coroa ou régio, pelo fato de o Inquisidor geral ser nomeado pelo rei e posteriormente nomear os membros do Conselho Geral, após consulta ao rei. Além disso, a Coroa é informada regularmente sobre a atividade do Santo Ofício, interferindo nas suas decisões e atribuindo explicitamente ao Conselho Geral o estatuto de conselho régio. Sobre isso, ver em BETHENCOURT, Francisco. Os Equilíbrios Sociais do Poder. In: MATTOSO, José (dir.) História de Portugal: No Alvorecer da Modernidade. Lisboa: Editorial Estampa 1993. Pp. 160-161.

${ }^{3} \mathrm{~A}$ intensidade da repressão aos seguidores e/ou suspeitos de seguir a Lei de Moisés manteve-se relativamente constante entre meados do século XVI e finais do XVII, seguindo-se um declínio gradual ao longo da segunda metade do século XVIII, declínio este decorrente das reformas conduzidas por Sebastião de Carvalho e Melo, o Marquês de Pombal (ROWLAND, 2010: 176). Francisco Bethencourt chega a se referir a esta constância na repressão à "apostasia dos cristãos novos" como um "regime de monocultura" (1993b: 104). De acordo com seu levantamento estatístico, os "delitos de judaísmo" representam 83\% dos processos do tribunal em Coimbra, 84\% dos de Évora entre 1553 e 1629 e 69\% dos de Lisboa (BETHENCOURT, 2000:318). Robert Rowland chega a números similares numa análise quantitativa de processos desses mesmos três tribunais entre 1536 e o início das reformas pombalinas, admitindo a mencionada queda progressiva nesses números ao longo da segunda metade do século XVIII (2010: 172-188).
} 
1777), D. Maria I (1777-1816) e D. João VI (1816-1826), neste último, desde o período em que governou como regente de fato, isto é, a partir de 1792. Na governança do Marquês de Pombal, a partir de 1750, no reinado de D. José I, observam-se mudanças graduais no funcionamento, atribuições e estatuto dos tribunais inquisitoriais ${ }^{4}$. Não se prescinde do Santo Ofício, considerado coluna indispensável para a manutenção de uma ordem social estabelecida na unidade entre altar e trono, em Portugal (RAMOS, 1988:42 e MONCADA, 1950:72-5). Tais reformas marcaram-se por uma orientação reformista ilustrada, que conjugava o discurso de modernizar o reino com a realização de modificações visando à preservação da ordem monárquica, da religião e da moral católicas (VILLALTA, 2011:2). É oportuno lembrar que o pombalismo não se incompatibilizou com a Igreja Católica. Pelo contrário, muitas das propostas pombalinas têm sua origem e devem seu êxito à estreita colaboração por ele recebida de personalidades do clero e de congregações religiosas, o que explica o caráter cristão e católico do qual se revestiu a Ilustração Portuguesa (BOSCHI, 1994:107).

Entre as mudanças que incidiram de forma mais aguda no funcionamento do Santo Ofício português, destaca-se o fim da diferenciação entre cristãos velhos e cristãos novos, o que fez com que muitos dos procedimentos desses tribunais perdessem a sua razão de ser (SARAIVA 1994: 209-11). A função do Santo Ofício deixa de ser a perseguição e vigilância de seus "inimigos tradicionais". A defesa da ortodoxia dirigiu-se a outros agentes. São eles, principalmente aos ímpios, heréticos, maçons, libertinos e livres pensadores que, com suas ideias e práticas heterodoxas, abalariam os alicerces da sociedade portuguesa do Antigo Regime (RAMOS, 1988b: 176). Dispensando uma atenção maior ao termo libertino vemos que o mesmo traz uma gama bem variada de significados. No $2^{\circ}$ volume do dicionário de Antônio de Morais e Silva (1789), o termo designa "aquele que é licencioso na vida", como também o indivíduo que "sacudiu o jugo da revelação" e presume que "somente a razão pode guiar, com certeza, no que respeita a Deus e à vida futura" (1789:221). Entende-se como libertino, no século XVIII, um indivíduo que questiona os dogmas da religião revelada, autoridades políticas, religiosas e censórias, contrariando toda uma ordem social absolutista, firmada na unidade trono e altar. Este termo passa a compor o vocabulário das autoridades do

\footnotetext{
${ }^{4}$ As reformas mais agudas no Santo Ofício ocorreram entre o fim da gestão do Inquisidor geral D. Nuno da Cunha e Ataíde, em 1750, sendo esse cargo, a partir de 1758, ocupado por uma série de Inquisidores gerais diretamente submetidos ao Marquês de Pombal (RAMOS, 1988:42). Ocorreu, entre outras modificações, a retirada da atribuição de censura de livros do Santo Ofício, em 1768 - com a criação da Real Mesa Censória-, a vedação dos autos de fé públicos e da impressão das listas de penitenciados, bem como um crescente controle da Coroa sobre esta instituição (RAMOS: 42-3). Incluem nas reformas a supressão da tortura e a criação de uma série de mecanismos que teriam a função da ampliação da defesa dos acusados (MONCADA, 1950:77).
} 
Estado português. Cumpre ressaltar ainda que, mesmo na documentação inquisitorial, de tribunais que se dedicavam ao combate da heresia, ideias e práticas desses libertinos eram apresentadas, aqui e acolá, com colorações políticas (VILLALTA, 2009: 513) ${ }^{5}$.

Esses alicerces da sociedade de Antigo Regime mantinham um sistema de poder político que se configurou dentro de um contexto em que a Igreja, a Coroa e a aristocracia sustentavam uma a outra na composição das estruturas de poder. Numa sociedade de corte, os privilégios de cada um desses setores dependiam em certo grau dessa harmonia. Cabia à coroa o papel de zelar pelo equilíbrio dessa rede de interdependências, derivado de teorias coorporativas sobre a sociedade, em que o monarca representava o corpo social e político. Assim sendo, a ele eram atribuídas funções de justiça, entendida como distribuir benesses e castigos respeitando direitos e privilégios, assim como preservar a religião e a boa ordem (BICALHO, 2005:21). O Santo Ofício é mantido e reformado para o combate do que as autoridades viam como uma "tríplice conspiração" urdida contra o altar, o trono e a sociedade civil, empreendida a partir de espaços de sociabilidade como, por exemplo, as lojas maçônicas de Portugal e da América portuguesa (NEVES, 2002: 131-2).

\section{Valorização e temor do saber letrado}

O reformismo português contribuiu indiretamente para o advento dos chamados libertinos em alguns setores da sociedade, em especial os setores médios e altos. Isso aconteceu especialmente devido a ideias e práticas "ilustradas" ganharem divulgação por meio de material impresso que circulava pelos domínios de Portugal. Isso se deveu especialmente a dois fatores, que são as mudanças na educação formal e uma maior difusão da leitura. No que tange a educação formal, pensadores como Luís Antônio Verney contribuíram com a difusão de concepções sobre a mesma orientadas por ideais ilustrados, em que se condenou o aristotelismo escolástico, amplamente difundido pelos jesuítas, além do combate a formas supersticiosas e fanáticas de religiosidade. Forma-se algo que pode ser definido como uma elite mundana letrada que assume abertamente o papel de porta-voz do público, que tenta representá-lo e formar seus julgamentos (CHARTIER, 1990:47 e ARAÚJO, 2004:201). Difunde-se ainda a noção de que se deveria modernizar a educação para se modernizar Portugal, difundindo-se o pensamento científico newtoniano, sempre em 
função da utilidade pública e do bem comum (MONCADA, 1950: 24-5). Sobre uma maior difusão da leitura, uma historiografia recente fala sobre uma espécie de "febre de leitura" no século XVIII (ABREU, 2008: 344). Além de uma maior circulação de impressos, ocorreu uma substantiva mudança nas práticas de leitura, observando-se uma transição da predominância de formais intensivas, baseadas na repetição e solenidade perante os cânones, para formas extensivas, menos reverentes e com maior liberdade do leitor (CHARTIER, 2009:143-6 ). Ao longo de todo o século XVIII até início do XIX, observou-se ainda em Portugal e na América Portuguesa uma crescente diversificação do público leitor, além de um aumento do número de estabelecimentos em que se vendiam livros e de encomendas dos mesmos de diversos países europeus (ABREU, 2009:8-10)

Também a partir da segunda metade dos setecentos, o clero perdeu parte de sua importância e poder, ainda que seguisse como apoio importante para a manutenção da ordem (BLANCO MARTINEZ, 1999: 62). Em Portugal, discute-se nesse período ajustes de seu estatuto, como o fim de suas imunidades, privilégios e domínio plurissecular da educação formal, que para autores do período era causa do atraso português em relação às demais nações europeias (ARAÚJO, 2003:60-1). O controle mais firme do clero pelo Estado, do Santo Ofício e da censura passou a ser encarado como necessidade para a modernização do Reino. Um "contra-efeito" desse processo foi a difusão, especialmente nos estratos médios da população, de atitudes e perspectivas menos respeitosas e reverentes em relação ao catolicismo, ao clero e as instituições a ambos ligadas (MONCADA, 1950: 18-9). Essa postura perante o catolicismo que é característica de uma conjuntura discutida por Roger Chartier sobre a França na segunda metade do século XVIII, qual seja, a dessacralização do mundo. Entende-se aqui como dessacralização, que não se confunde com descristianização, um processo em se desenvolve uma atitude crítica, livre, menos reverente e obediente em relação a pontos antes considerados intocáveis (2009:147-170). O impacto mais notável desse processo nas formas de pensamento foi a emergência de perspectivas mais críticas em relação à sociedade, religião e política (VILLALTA, 2009:24).

Analisando a documentação inquisitorial, entre processos, sumários, apresentações e denúncias em que pessoas foram acusadas de práticas libertinas, observam-se representações bem distintas sobre o saber letrado. É notável a existência de um confronto entre, de um lado, a valorização do saber livresco e, por outro, a permanência de um temor relacionado ao mesmo conhecimento. Considerava-se que ele poderia ser nocivo na medida em que estimulasse práticas heréticas. Ao mesmo tempo, este mesmo saber poderia ser um meio de se combater essas mesmas ideias e práticas heréticas, fornecendo subsídios necessários para 
exercício do poder e melhor conhecimento de doutrinas consideradas sediciosas e subversivas (VILLALTA, 1999:312-7). Existia ainda a percepção de que a cultura letrada e o conhecimento erudito serviriam à coroa fornecendo recursos para que fossem combatidos alguns aspectos da mentalidade tradicional portuguesa, como os milenarismos e o sebastianismo (VILLALTA, 2009: 137). Em relação aos livros e a leitura, entendia-se ambos tinham um grande impacto social e individual, que chamavam muito a atenção dos pensadores europeus. Ler causaria impactos físicos, mentais e sociais drásticos. Considerava-se que leitura jamais seria uma prática inócua e que pode causar enormes e diversos efeitos naqueles que a praticam, o contato poderia ter impactos graves na ordem e na moral (ABREU, 2008:347).

Em alguns documentos inquisitoriais, é de se notar algumas evidências de que os livros e as práticas de leitura serviam aos libertinos como meio de fundamentar suas proposições heréticas. Ataques ao Papa, à Inquisição, ao estado eclesiástico, além do entendimento de que a religião servia para repressão do homem na sociedade, possuíam alguns pontos de convergência com posições defendidas em alguns livros proibidos (VILLALTA, 2009:123). Nessa mesma documentação, notamos o aparecimento de espaços para a circulação de livros, debates de ideias, leituras públicas, entre outras práticas. Um indício de uma sociabilidade similar aos que Robert Darnton chama de boemia literária,na França pré Revolução. Transgressora dos valores do Antigo Regime ao formar espaços igualitários, de debates de ideias heterodoxas e que contrariam dessa forma as hierarquias da sociedade aristocrática e cortesã (1987:46-7). A leitura oral era disseminada e as trocas de livros entre esses letrados eram comuns (1987:71). Surgem ainda evidências de como tais heterodoxias surgiram da articulação entre debates orais, conversas e discussões juntamente com os livros, esses últimos serviram para legitimar ou dar um ar de erudição a certas proposições heréticas (VILLALTA, 2009:118). O conhecimento erudito atribuído aos investigados é também parte importante em diversas caracterizações de suas possíveis culpas.

Um caso que vem a ilustrar bem o quadro acima descrito é o de Manuel Galvão. Formado em filosofia e natural da Bahia, acusado de libertinagens no ano de 1778, juntamente com outros estudantes da Universidade de Coimbra, alguns notáveis ${ }^{6}$. Entre algumas das culpas que lhe foram atribuídas, constam algumas vivenciadas com seus colegas

\footnotetext{
${ }^{6}$ Como Antônio de Morais Silva, Francisco de Melo Franco, Manuel Joaquim Henriques de Paiva, Antônio Pereira de Caldas, do Brasil; João Laureano Nunes Leger, Francisco José de Almeida, José Maria da Fonseca, Jerônimo Francisco Lobo, Vicente Júlio Fernandes, Nuno de Freitas, Diogo José de Morais Calado, José Antônio de Melo e Antônio Caetano de Freitas, nascidos em Portugal e ainda Antônio da Silva Lisboa, de Luanda, Angola. (CÂNDIDO, 1994: XX-XXII).
} 
de universidade, como Joaquim Cavalcante, "Mello", "Moraes" e Joaquim José da Silva. Com seus colegas, nos idos de 1777, Galvão mantivera discussão:

sobre pontos da Religião, especialmente, com o sobredito Mello, que fez Baxarel em Medecina, queizandosse da facilidade com que este despistava sobre o Materialismo, de que era loquáz, pelo sistema digo sequaz pela leitura do Sistema da Natureza, que dezia o mesmo Moraes lera aquelle, mas não lhe lembra o autor, e sopoem ser Mirabó. (Arquivos Nacionais da Torre do Tombo, Processo número, 13367. Culpas contra Manuel Galvão: 9-10) ${ }^{7}$.

Acrescentam-se, ademais, informações sobre ideias e condutas de outros estudantes, tais como:

[a] facilidade do dito Joaquim Joze da Silva comer carne toda a Quaresma com huma mulher castilhana, que tinha em sua companhia, e persuadindo Diogo Joze ao dito Morais, que não fugisse, dando lhe para isso algumas razoens, pelas quais não devia fazer, respondeo, que se arependia de lhe ter comonicado a sobredita sua rezolução, e pasado algum tempo, dezaparescendo o dito Morais, suspeitarão, que se tinha escondido, ao que o persuadio o dito Diogo Joze, e que assim esperasse athe se o buscavão pelo Santo Officio, para o prenderem, com o que se auzentaria. (ANTT, Processo 13367:10)

O sobredito Manuel Galvão, ao lado de outras pessoas, é apresentado como um conhecedor do livro Sistema da Natureza, ou Système de la nature ou des loix du monde physique \& du monde moral (1770), publicado pelo Barão D'Holbach, em francês, sob o pseudônimo de Mirabeau. Galvão é também descrito na denúncia como loquáz quanto às suas ideias materialistas. No mesmo contexto, tal leitura convive com práticas como a de comer carne em dias proibidos pelos preceitos católicos juntamente com outros acusados. Voltando ao mesmo Manuel Galvão, a mesma testemunha afirmou que dele ouvira:

[...] algumas prepoziçoens ímpias, de que senão pode lembrar, por que pouco assistia ao dito Galvão, e ao jogo em que erão companheiros, do dito, os delle reo, dos quais [...] não sabe se se declararão com o dito Galvão, dos sentimentos, que tinhão errados a respeito da Religião [...] do dito Galvão so se lembra ouvido huma occazião disputar no Laboratorio de Quimica, e caza de Manoel Joaquim na prezença deste, com hum estudante chamado Alexandre cujo sobrenome não sabe, natural de Almeria, que neste anno se doutorou em Filozofia, sobre a Imortalidade da Alma, que defendia o dito Alexandre, e o dito Galvão dizia, que não somente era mortal, mas material, questão, que passava em forma de argumento, rindo se o dito Galvão, ao qual, com tudo, não ouvio desdizer, nem protestar contra o erro da sua aserção, que acabou dizendo, que os homens de grande juízo, tinhão mais

\footnotetext{
${ }^{7}$ Daqui em diante, será usada a sigla ANTT para se referir aos Arquivos Nacionais da Torre do Tombo, acervo documental onde constam os documentos utilizados neste trabalho.
} 
[....] do que os de pouco, dando a entender, que tudo era matéria, em que se emprimião as idéias, que fazião os mais actos do entendimento. (ANTT, Processo 13367:11-2)

Manuel Galvão, portanto, foi acusado de ter defendido publicamente em diversas ocasiões pontos sobre religião convergentes com os encontrados no livro supracitado, no caso, o materialismo holbachiano. Sistema considerado, por diversas razões, herético. Defende, por exemplo, a inexistência qualquer necessidade de se recorrer ao sobrenatural para explicar a formação de todas as coisas naturais, estando elas submetidas a regras universais de causa e efeito, absolutamente independentes de qualquer intervenção ou providência divina (D’HOLBACH, 1797:20). O conteúdo dessas acusações vem também a iluminar possíveis práticas de leitura do último quartel do século XVIII. Práticas que mais do que propriamente induzir pessoas à aceitação de determinados preceitos e sistemas, traduziram uma relação entre o leitor e esses livros que implicou numa ação ou uma série de ações concretas, as quais, muitas delas, podiam ser e foram consideradas heréticas. A simples posse de livros proibidos ou a informação de que circulavam nas mãos desse grupo denunciado não nos permite afirmar que eles espalhassem a heterodoxia religiosa e política. Entretanto, a leitura deles e sua sistemática difusão, sinalizadas pela suspeita da posse deles pelo denunciado e sua circulação na mencionada livraria, corroíam os pilares do Estado absolutista - a lei, a fé e o rei (FURTADO, 2006:75). Corroíam, no entendimento das autoridades, por sinalizarem as já mencionadas sociabilidades combatidas no Antigo Regime, as boemias literárias. Sociabilidades entre letrados durante a Ilustração, que ameaçavam as estruturas da sociedade absolutista por se organizar em torno de um estado igualitário -somente entre os paresimaginados, em que houve tentativas de abolir ou, ao menos, limitar distinções sociais entre os iniciados nestes círculos, proibindo-se demonstrações de deferência nos seus encontros (BURKE, 2011: 277). Grupos de ilustrados cujas práticas em comum eram firmadas numa noção de compartilhamento - no sentido de observar a realidade sob o olhar do outro- de perspectivas de mundo, opiniões e representações da realidade que adquirem feições políticas nítidas num mundo em que público e privado não possuem fronteiras muito claras. Torna-se possível que essas relações interpessoais assumam relevância política por ocuparem, no campo de valores da vida pública, o espaço indistinto entre estes dois campos (ARENDT, 1968:24). Há de fazer a ressalva de que colar tais ações heterodoxas a essas leituras era uma estratégia muito recorrente destes acusados a fim de aliviar suas próprias culpas perante a repressão inquisitorial (NOVINSKY, 1990: 361-364; VILLALTA, 1999: 342-3). 
No processo contra José Antônio da Silva, a leitura dos mesmos livros não foi destacada. Entretanto, há pontos de convergência entre algumas das proposições atribuídas a ele com ideias de pensadores da Ilustração críticos ao Catolicismo. Assim como no processo contra Manoel Galvão, nota-se uma interligação de condutas e ideias no mesmo acusado de libertinagem, que ajudam a construir um estereótipo do acusado desse tipo de crime da alçada inquisitorial: a licenciosidade sexual, a irreverência em relação à religiosidade e a incredulidade acabam por compor, no mesmo indivíduo, um quadro de comportamento censurável e objeto de vigilância e controle por parte das autoridades. Voltando ao processo: José Antônio da Silva, brasileiro, solteiro e estudante de medicina na Universidade de Coimbra, foi denunciado por quatro pessoas, entre as quais outro estudante do terceiro ano do seu mesmo curso- Antônio Nunes da Costa, então com 24 anos- de proferir proposições heréticas e de libertinagem. A tipificação do libertino se faz perceber na descrição minuciosa feita pelos denunciantes. O denunciante compareceu diante de Manoel Antônio Ribeiro, inquisidor de Coimbra, aos 23 de julho de 1778, para denunciar os seguintes fatos:

Que haverá sinco annos, estando elle denunciante em huma tarde em coverçassão as portas dos Gerais da Universidade com outros estudantes hum dos quaez era João Gomes, [...] canonista sobrinho de João Antonio de Bezerra e Lima professor da Rethorica em cuja caza asistia no dito tempo no Sitio da Feira defronte da Sé Nova desta Cidade, que a tres annos se formou, se retirou para Vianna sua Patria, no Minho [...] e dos outros estudantes não esta certo quem erão, sucedendo falarce na dita converçassão nos padres da Companhia, e dizer [a]o sobredicto João Gomez, que elles tinhão muito más qualidades, e que justamente forão expulsos do Reino, respondeo elle denunciante, que assim seria porem que elles tinhão muitos Santos, que veneravão na Igreja, e isto replicou o dito João Gomez, que elles serão muito vaidozos, e cegos da ambição e [...] dos bens terrenos, e que os Pontifices nos Primeiros secullos canonizarão muitos santos só por qualquer ter morrido martir, sem examinarem o fim, [o motivo] que tiverão para sofrer o martírio, declarandoos por santos sem outra formalidade; muitos delles, pela vaidade de terem na sua Geração quem foi na Igreja venerado por Santo, por termo constantes, fortes, robustos, sofrerão a morte, sem ser pela fé, e que assim estariam adorando muitos lados de pessoas, que estarião no Inferno, ao que lhe pareseu, que assim elle denunciante, como os mais declarão, a converçassão continuou em outras matérias [...]atentantes a religião. (ANTT, Processo $n^{\circ}$ 028/13-336. Processo contra José Antônio da Silva: 1-2).

A denúncia se centra nas matérias de religião e, secundariamente, da moral. No trecho supracitado, há uma crítica aos mártires religiosos e às suas canonizações. José Antônio da Silva foi acusado de afirmar que alguns dos santos mártires da Igreja Católica, foram movidos por sentimentos terrenos, como os da ambição e a teimosia, e não pela fé. Por sua vez, os 
primeiros pontífices os teriam canonizado sem os examinarem de forma adequada, especialmente suas mortes. Vai mais longe ao dizer que, a despeito de suas canonizações, muitos deles, os quais as pessoas veneram, estariam no Inferno. A denúncia prossegue.

Dice mais, que também lhe referira o mesmo Antonio Joze da Foncequa Bordallo, que o sobredito Joze Antonio não ouvia Missa nos dias de preceito, se alguma vez fazia, estava na Igreja em pe, sem atenção, apenas a elevação da Hostia, e Calix ajoelhava com hũ joelho somente, talvez por evitar, o escandalo; e que tambem comia carne nos dias em que a Igreja prohibe, e que ele ordem dava a sua ama, que nos dias de Peixe senão achace fresco se nao embaraçasse em levar lhe carne, porque elle também senão embaraçava em comella. (ANTT, Processo no 028/13-336:2-3).

Era acusado ainda de desobediência frequente de preceitos católicos, como os jejuns obrigatórios, a recusa em se ajoelhar durante a missa. Usaria ainda da dissimulação para "que se evitasse escândalo", de acordo com uma possível dedução do denunciante, ajoelhando-se somente com um dos joelhos em certas ocasiões. Além disso, censurara diretamente a um soldado do regimento que fazia as orações ao Santíssimo e se ajoelhava para tanto. Por fim, conclui-se esta parte da denúncia quando se afirma, na denúncia, que:

(...) que o sobredito Joze Antonio tinha odio, e raiva a clerigos, e frades, e que não falava a hum irmão, que tinha [,] pelo so motivo de ser frade; e que o motivo, que o dito Antonio Joze da Foncequa tivera para perssuadirce, que o dito Sebastião, moço do Coro da Se, estava mal instruhido pelo sobredito Joze Antonio, fora por lhe dizer o dito Sebastião, que o pecado de Molices praticadas com o mesmo sexo não era pecado, por que no sexto preceito do Decalogo do se prohibia a fornicação, e que isto lhe dicera querendo aliciallo para os ditos actos torpes. (ANTT, Processo $\mathrm{n}^{\circ}$ 028/13-336: 4).

Ademais, o denunciado odiaria o clero e seus representantes, especialmente o clero regular, chegando ao extremo de recusar-se pessoalmente em conversar com um seu irmão que era frade. Por fim, o estudante daria "má instrução" a um rapaz do coro da Sé chamado Sebastião, dizendo-lhe que o pecado da molície, no caso, a masturbação, não seria pecado contra o sexto preceito, já que ele somente se referia á fornicação, segundo a interpretação feita pelo estudante. Todos esses elementos do processo compõem um perfil se conforma à noção mais ampla, então em voga, do que seria a libertinagem. 
Nos dois casos citados, temos em comum o ambiente da Universidade de Coimbra, pois ambos os acusados tinham ligações com a instituição, sendo um já formado e outro, estudante. Tudo o que colhemos sobre esse contexto universitário nos conduz a pensá-lo como um lugar propício à circulação de livros e ideias libertinas (NOVINSKY, 1990: 357370). Deve-se ressalvar, porém, que esse tipo de comportamento se dava de formas diferenciadas, com particularidades. Nessas duas denúncias podemos pensar numa relação de periculosidade dos livros, na visão dos denunciantes, ligando-os diretamente com a formulação e divulgação de proposições heréticas por parte dos acusados.

A documentação não fornece informações suficientes para que se possa afirmar com veemência muito sobre as práticas de leituras desses denunciados. O que se pretende salientar nos dois exemplos é que existe uma forte preocupação das autoridades com pontos que podem ter ligações diretas ou indiretas com a formulação de heresias. A leitura inventiva dos livros proibidos ou não, assim como conversas pessoais entre leitores e um exame crítico, cada vez mais frequente, de pontos de religião, representavam ameaças sérias e pertinentes à alçada inquisitorial. Desde o século XVI, a ciência dos inquisidores acerca da erudição dos acusados e réus era considerada fundamental em suas investigações. Proporcionaria, por exemplo, um leque mais amplo de opções para se apurar casos de protestantismo, molinosismo, além de correlações entre as heresias e o judaísmo, milenarismos, práticas ligadas à magia, entre outros (VILLALTA, 1999:330-6). Já na segunda metade do século XVIII, esse aspecto se torna importante para a identificação dos libertinos. Como já foi citado, o conhecimento estava sendo valorizado dentro do contexto reformista em Portugal. A presença ou a falta de um conhecimento erudito, socialmente reconhecido e autorizado era um aspecto importante aos inquisidores quando eles se debruçavam sobre os processos referentes às heresias. Essa situação parece evidenciar-se em relação a Rodrigo Sodré Pereira, acusado de libertinagens e proposições heréticas em 1792 e cujo processo ficou inconcluso devido sua morte, ocorrida antes do da apuração da denúncia. Segundo a acusação feita pelo padre Manoel Alberto sobre suas “doutrinas pagãs" e sua "libertinagem”, Rodrigo Sodré:

[...]vive com sua cunhada viúva, depoiz da mórte de seu irmão como cazádo de que tem duas mininas, fáz gála de fazer ver as suas vergonhózas partes, e tráz com az suas dânozas doutrinas alguns arrastrádoz pello cégo caminho da perdição como hé hum seu Sobrinho natural q. tanto elle, como o dito Sobrinho diz q. não deve confessar os seus peccados a hum sacerdote homem come elles; e publicáraõ na Rua do Tijôlo ${ }^{8}$ da Bahia da janéla abaixo

${ }^{8}$ Rua do Tijolo, no centro de Salvador, na Bahia. 
da caza d'hum Letrádo da Coxeira isto mesmo; e q. havia huma $S^{\text {ta }}$ Bárbara, e hum $S^{\text {to }}$ Gerónimo advogádo doz trovoins e que livrava das mortes repentinas'; que maior felicide.dizia elle Rodrigo Sodre Per $^{\mathrm{a}}$ que ter hum homem, huma tal mórte para se ver Livre das penalides que ella cauza, poiz a Alma morre com o corpo da mesma fórma q.os irracionais e q. não havia Inférno; [...] So Sócio doz seus dezaforos a outro semilhante hé o doutor Máta da cidade da Bahia; [...] [nas] fazendas da [sua] cunhada, se poz nú em pello diante da fazenda Da família da caza e Fazendo Cóvas na Cáza deitou vinho no xão e outros varioz socioz, e o bebeu de cócocas; hé temível o tál sugeito e ladrão manhozo, dizem ser judeu por parte da Mãy e todas as suas acçoins são fora do temor de Deus q. não pença mais q. em inganoz, e ladroeiras, advertindo porem que o Sup ${ }^{\text {e }}$ não forma esta queixa pello este ser inganádo em quatro centoz mil reis, q. já mais não verá, mas sim pello q. tem ouvido, e perzenciádo, que o que aqui se refére não hé nada em comparaçaõ daz suaz liberitinagens, que só tirando uma particulár rezidencia pellas pessoas timorátas da Patativa Freguezia de $S^{\text {to }}$ Amaro da Purificaçaõ e daz vizinhanças do Pay de dito Rodrigo hé que se póde descubrir o que elle hé, q. me persuado se a porporção de sua maxavelhice e talento tivéra Estudoz teríamos máis hum Hereziarca; Conzta que o denunciádo vem a esta Corte; para o que já tem passaporte do Governador D. Fernando de Portugál e que virá em qualquer doz primeiroz navioz q. Chegarem da Bahia, (ANTT, Inquisição de Lisboa, Processo 028/01810. Processo contra Rodrigo Sodré Pereira:3v-4).

O espectro das acusações contra Rodrigo Sodré Pereira é bastante amplo. Vemos uma conduta sexual licenciosa, que pode ser notada em seu gosto por se "fazer ver suas vergonhosas partes" em público, assim como viver ilicitamente em concubinato com a viúva de seu irmão. Além disso, as diversas proposições heréticas das quais foi acusado de proferir serviram para que seu acusador traçasse um perfil altamente escandaloso, de acordo com os preceitos católicos (SCHWARTZ, 2009: 38-40; Regimento do Santo Officio da Inquisição dos Reinos de Portugal, 1774: 109-12). Negava a existência do Inferno, hostilizava imagens de santos, afirmava que a alma humana morria tal qual a alma dos seres desprovidos de intelecto. Ademais, difundia e praticava a ideia de que não se deveria confessar a um sacerdote que, segundo seu ponto de vista, seria um homem igual a ele. Conduzia seu sobrinho nos mesmos princípios.Também, de acordo com a denúncia, afirmou contar com a proteção do Governador D. Fernando Portugal e Castro, da mesma forma que teria acontecido com Cipriano Barata e Marcelino Veloso (VILLALTA, 2009:74). Chama a atenção também o fato de o acusador mostrar-se persuadido de que, se ele tivesse mais estudos, de acordo com seu talento, poderia se tornar um grande heresiarca.

\footnotetext{
${ }^{9}$ Santa Bárbara e São Jerônimo, segundo a religiosidade popular, santos que protegem as pessoas das tempestades e mortes repentinas decorrentes delas.
} 
Os estudos e uma formação mais refinada, na visão do denunciante, poderiam vir a ser um fator que potencializasse o talento e "maxavelhice" de Rodrigo Sodré Pereira. Com mais estudos, talvez, este se tornasse um grande formulador de heresias -heresiarca -, alguém que viesse a ser reconhecido por suas ideias e práticas muito nocivas à Igreja Católica e, talvez, também a outras instituições. Vemos então um dos lados da ambiguidade já mencionada do reformismo português em relação ao conhecimento e a cultura livresca, no caso,ele sendo percebido como um caminho para a formulação de proposições heréticas e práticas heterodoxas. Percebe-se que à cultura erudita pode ser atribuído um peso negativo por parte da Inquisição, ao menos ela enquanto possível fomento de heresia.

$\mathrm{Na}$ apresentação de Maria Madalena Salvada vemos outros elementos que também podem nos servir para traçar este panorama sobre a relação do tribunal do Santo Ofício com o conhecimento expresso pelos réus e a relação estabelecida entre ele e a formulação das proposições. Nesse processo vemos que a falta dessa forma de conhecimento que fora apresentada por alguns réus a fim de atenuar suas culpas. Um exemplo neste sentido, Maria Madalena foi acusada por libertinagens e proposições heréticas, e que se apresentou à Inquisição de Lisboa numa audiência para confessar algumas de suas práticas para "descargo de sua consciência e merecer a piedade e mizericordia d'Esta Meza" (ANTT, processo n028/09275. Apresentação de Maria Madalena Salvada: 1). Na ocasião, confessou blasfêmias, desacatos, proposições heréticas, além de práticas sexuais licenciosas, implicando em tudo isso seu amante Joaquim José Vieira Couto, de quem descobrira vários objetos ligados â maçonaria. Aos 27 dias do mês de janeiro de 1804, se apresentou ao inquisidor Manuel Estanislau Fragoso, e confessou que:

(...)tendo ella Sido conduzida preza de Caza de Joze Joaquim Vieyra Couto para o recolhimento de Nossa Senhora da Conceição do Castello d'Esta Corte; e vendo-se privada de toda a comunicação externa, e em grande aperto profferio, em hum dia, estando naprezença de hua Imagem de Jezus Christo com a Involação dos Perdoens = Se a mesma Sancta Imagem, ou o Seu Original, tiveSse o poder que se lhe atribuia, não havia de padecer nem Sofrer os martyrios que se dizia; e que Deos não tinha parte nella mas sim o Diabo; e por iSso não queria rezão por que não havia Inferno, e outros Absurdos d'Esta qualidade, emcaminhados amanifestar falta de Religião; (ANTT, processo n028/09275. Apresentação de Maria Madalena Salvada: 2) 
Prosseguia a confissão, dizendo que durante todo o tempo em que abandonou seu marido para viver para "fins libidinosos" com Joaquim José Vieira Couto não ouvira missa e nem praticara qualquer outro preceito católico, além de ter lições na língua francesa. Além disso, há diversos indícios na apresentação de que nessa casa em que vivera, tivera contato com romances franceses (VILLALTA, 2012: 92-93). Além disso, narra que ouvira de Couto que:

em hua ocazião em que ella declarente, atizando hua Vella se queimou em hum Dedo, e comparuouentão então por eSse motivo aquelle Ardór como das pennas do Inferno, lhe dicera o mesmo Couto, que não havia Inferno, porque debaixo do chão não havia Fogo, que não consistia senão porque debaixo do chão não havia Fogo, que não consistia Senão em hua Escuridão onde não havia Tormentos (ANTT, processo nº28/09275: 2v)

Completava, dizendo que Couto:

lhe trouxera hum livro de Novellas em que se tratava da Firmeza, a Amizade de doys Amantes: e que tambem lhe mostrára dói livros francezes com estampas de acçoens torpes, e indecentes, afirmando-lhe ter mais oBraa daquella natureza,mas que os tinha emprestado:Dice mais que também o referido Coutto estando sós continuadamente lhe persuadia que as Acçoens Libidinozas não erão pecado, porque Deos não se embaraçava com Semilhante Couza e deixava a Vontade Livre para cada hum usar das partes de seu Corpo como quizeSse: (ANTT, processo no028/09275: 3)

Sobre o pecado ainda o definia que ele somente existia quando "falta de Socorrer o proximo por caridade, ou em afliçaõ, podendo-o fazer he que não era bom" (ANTT,processo no028/09275: 4). Maria Madalena Salvada, mais do que ter uma conduta sexual licenciosa enquanto morava na casa de José Joaquim Vieira Couto, teria se entregado a ideias, leituras e práticas libertinas e heréticas. Defendeu proposições conhecidas, tais como a negação da existência do Inferno e do Purgatório, a defesa da fornicação simples como não sendo pecado (VAINFAS, 1997:17), já que Deus teria deixado os homens com vontades livres para que cada qual usasse do corpo como bem entendesse (ANTT,processo n028/09275: 4). Além disso, desrespeitou preceitos da Igreja, ignorando os dias de jejum e não ouvindo missas, por exemplo. Teria lido livros proibidos franceses, possivelmente romances com estampas licenciosas, de acordo com a apresentação. Os mesmos livros franceses, novelas, de acordo com os termos que foram pela ré na apresentação,seriam mais 
numerosos do que ela declara, tendo sido emprestados a algumas outras pessoas por Couto (ANTT, processo $\left.n^{\circ} 028 / 09275: 4\right)$. O documento não chega a detalhar muito acerca desses possíveis empréstimos. Maria Madalena Salvada, além disso, apresenta a si mesma como uma pessoa induzida pelas más companhias com quem vivia. A fim de demonstrar seu arrependimento, a ré, ao ser novamente interrogada:

Dice que suposto isso assim sucedeu como tem confessado, comtudo nunca dera ascenço interno as ditas douctrinas, e que histo prodéra mais de fragelidade Sua, do que de malicia, Visto ser ella hua mulher sem estudos, nem Luzes alguas, e de facil sedução por mizeria Sua. (ANTT, processo $\left.n^{\circ} 028 / 09275: 18\right)$

A falta de "luzes", neste caso, foi responsável por ter se deixado seduzir pela heresia. Tal justificativa, ademais, foi aparentemente aceita pelo Santo Ofício, como se sucedeu ao fim da apresentação em que lhe deu a sua absolvição ad cautellam decorrente da fragilidade da ré, no sentido de que ela fora mais facilmente seduzida por libertinos dotados de maior erudição. Justificativa similar foi dada por Gonçalo Garcia, natural da Paraíba, marinheiro das armadas inglesa e portuguesa. Aos dois de abril do ano de 1799, quando, segundo o documento, tinha a idade de quarenta anos, se apresentou perante o mesmo inquisidor Manuel Estanislau Fragoso a fim de confessar algumas de suas culpas. Delas se destacam inumeráveis atos sodomíticos completos com diversas pessoas do seu mesmo sexo, e mesmo com alguns animais, dentro de um espaço de doze anos em que esteve alistado na marinha inglesa (ANTT, Processo $\mathrm{n}^{\circ}$ 028/Cx. 1577/13638. Apresentação de Gonçalo Garcia: 2-3). O convívio com pessoas de religião e costumes contrários à religião de seu batismo, assim como sua rusticidade (ANTT, Processo $n^{o}$ 028/Cx. 1577/13638: 4;7) são mencionados na mesma apresentação como atenuantes de seu comportamento e da não observância dos preceitos católicos. Ele também foi, como Maria Madalena Salvada, absolvido ad cautelam (ANTT, Processo $\mathrm{n}^{\circ}$ 028/Cx. 1577/13638: 7). Já no processo referente ao adido ao serviço militar francês residente em Lisboa Pedro Manuel Bernes, de 16 de março de 1795, o acusado menciona não ter recorrido aos livros heréticos a fim de dar sustentação a suas proposições, no caso, a descrença nos castigos eternos e a não observância dos preceitos obrigatórios do catolicismo. Menciona ainda prazer em enfurecer os eclesiásticos, dizendo que tais proposições e a sua liberdade com pontos de religião serem naturais em meio à sua mocidade (ANTT, Processo nº 028/09744. Processo de Pedro Manoel Bernes: 6-7). 
Com base nesses documentos não se pode afirmar se tal uso da falta de erudição como forma de atenuar suas culpas era uma ação deliberada dos acusados. Ou ainda se atenuar culpas por conta de uma rusticidade atribuída aos acusados era uma prática comum das autoridades. Entretanto, podemos inferir que essa mesma rusticidade, apresentada como responsável por suas condutas e formulações heréticas, bem como uma suposta facilidade de sedução por parte de libertinos mais letrados por conta da cultura erudita, são percepções que claramente tem alguma aceitação por parte das autoridades.

Um exemplo que vai por um caminho contrário aos dois analisados acima é referente ao bacharel Francisco Luiz Mariz Sarmento, morador do Ceará. Em sua denúncia, fica explícito um receio do denunciante quanto à possibilidade deste homem, descrito como culto e letrado, de seduzir pessoas de menos luzes. Foi acusado de libertinagens e blasfêmias pelo comissário Joaquim Marques de Araújo, em 1803. Entre as cinco acusações das quais este bacharel é objeto, atentemos à que se refere a livros proibidos.

Tertio: com a lição quotidiana de alguns Livros prohibidos; como são = La Phylosophie Du bom sens Du Marquiz d'Argent= La Antiquité de voilé par sés usages de Mr. Boulanger $=\mathrm{V}^{\mathrm{a}}$, que o denunciado houve da livraria do Bacharel Manoel Leocadio Rademaker, hoje ouvidor e carregador da Comarca da Parahiba (ANTT. Processo nº28/13977. Denúncias contra Francisco Luiz de Mariz Sarmento: 3) .

O comissário, concluindo detalhadamente a denúncia, apresenta uma recomendação logo após mencionar a comparação trocista que Sarmento teria feito entre uma pomba, que representa a Terceira Pessoa da Santíssima Trindade no altar, com seu cavalo do tipo ou raça rossa pombo (ANTT. Processo nº28/13977. Denúncias contra Francisco Luiz de Mariz Sarmento: 4). Afirmou que:

Esta propozição, que decide inteiramente da irreligião do denunciado, pode fazer grandes progressos, por ismo [isso] mesmo que proferida, entre huma gente, pela maior parte ignorante, por hum homem acreditado de instruído pela sua formatura, e que tem tido [...] na mão do Governo desta Capitania, onde os habitantes seguem cegamente todos ditames e máximas dos que manejam a Governança dela. (ANTT. Processo nº28/13977: 4).

O risco da sedução dos ignorantes por parte desses "libertinos letrados" se faz ver explicitamente na fala do denunciante Joaquim Marques de Araújo. Essa fala sugere que, naquele contexto, aos olhos dos oficiais da Inquisição, havia um saber erudito cujos efeitos seriam perniciosos se atingisse a "gente ignorante". 
Percepção, em alguns pontos, similar, ao que se vê no processo contra o frei Henrique de Jesus Maria, religioso da província de Santo Antônio dos Capuchos e sacerdote. Foi acusado de solicitação, ler livros proibidos e dizer proposições heréticas -tais como de que as "pessoas deveriam professar ora uma religião, ora outra, usando a razão e liberdade que lhe foram dadas por Deus", ao ponto de um discípulo seu ter dito que ele seria "pior que Voltaire" (ANTT. Processo no 028/06239. "Processo contra Henrique de Jesus Maria": 3). Na acusação de outro religioso, o frei Henrique de Jesus Maria teria dito ao padre Joseph de S. Thomas para que fizesse em seu lugar uma pregação sobre a vida de São Francisco, uma vez que Jesus Maria não queria que, após falar no púlpito sobre as chagas do dito santo - que ele afirmara serem mentira- fosse ele elogiado por "conseguir mentir" (ANTT. Processo no 028/06239:4). Uma leitura possível dessa fala poderia sugerir uma resistência ao defender no púlpito um ponto do qual desacreditava, tendo como preocupação o convencimento dos que ouviam das mentiras as quais haveria de pregar.

Existia a ideia em relação ao homem ilustrado sobre ser um militante ativo de seus ideais, cosmopolita e prosélito, esforçando-se sempre para compartilhar suas ideias com seu entorno social, ainda que elas se contraponham a alguma ortodoxia vigente (BLANCO MARTINEZ, 1999: 126-7). Seria possível que no campo das representações dos denunciantes, tal imagem do homem ilustrado também se identificasse a esses libertinos. $\mathrm{O}$ risco existiria na medida em que eles militassem e divulgassem tais proposições e pontos de vista heterodoxos para seu entorno social.

Em suma, concebia-se que havia uma erudição e um conhecimento livresco singulares, esteio das proposições heréticas e irreligiosas pronunciadas pelos acusados e réus de libertinagem e heresia; esse mesmo saber, além disso, poderia por em risco aos não letrados, os "ignorantes" e rústicos. Ao mesmo tempo, por isso mesmo, a ignorância em relação a tais "saberes libertinos" e, de resto, a ignorância relativa ao saber erudito em geral, servia como justificativa que aliava os "erros" cometidos pelas gentes de maior simplicidade. Portanto, havia certa ambiguidade da parte da Inquisição com relação ao conhecimento, a circulação de livros e leituras no mundo luso-brasileiro, sendo isto ainda presente mesmo no período do Reformismo Ilustrado. 


\section{Conclusão}

O Regimento de 1774 surgiu num contexto que pedia novos parâmetros de ação, conforme demandas novas. O fortalecimento do poder estatal e a centralização do mesmo nas mãos da coroa atingiu também o funcionamento do Santo Ofício. Ao invés de uma vigilância do judaísmo e práticas judaizantes dos cristãos novos, tais tribunais, juntamente com outras instituições policiais e censórias, passou a ter como prioridade a supressão de práticas heterodoxas, algumas das quais consideradas como libertinas. A unidade entre a cristandade, monarquia e sociedade de corte estaria, nessa percepção, ameaçada pelos ataques feitos pelos libertinos aos paradigmas fundamentais que davam sustentação a esta harmonia. Esses livres pensadores, questionadores da moral, das autoridades civis e eclesiásticas e de todos os dogmas estabelecidos, significavam um risco de corrosão das referências fundamentais dessa sociedade de corte, segundo a percepção das autoridades. Nisso, a importância da cultura livresca e letrada passa ocupar um lugar de destaque, estando no centro de diversas representações dessas autoridades quanto à formulação e difusão das ditas práticas heterodoxas.

Esse saber erudito pode fornecer às pessoas menos escolarizadas, rústicas conforme a terminologia comumente usada nos documentos, meios para praticarem a religião de forma mais racional, longe de práticas supersticiosas ou irreligiosas. Mas também oferece riscos, uma vez que serve de arcabouço a livres pensadores, "ímpios", libertinos e irreligiosos para a formulação dos desvios de fé. O valor atribuído ao saber erudito também é, muitas vezes, considerado na documentação inquisitorial, visto no centro muitas preocupações com possíveis riscos de libertinos de formação erudita mais sofisticada seduzirem facilmente rústicos com suas ideias.

Por fim, há de se pensar na possibilidade de que tais representações sobre a importância e poder da cultura letrada pudesse servir a tais acusados ou mesmo réus como forma de se esquivar de condenações ou de atenuar penas a eles aplicadas pelo tribunal. 


\section{REFERÊNCIAS BIBLIOGRÁFICAS}

ABREU, Márcia; Sob o olhar de Príapo: narrativas e imagens em romances licenciosos setecentistas. In: Imagens na História, Capítulo, ed. 1, HUCITEC (Aderaldo \&Rothschild). 2008. Pp. 344-73

; Os lugares dos livros: comércio livreiro no Rio de Janeiro Joanino. In: Floema - Ano III, n. 5 A, p. 7-30, out. 2009.

ARAÚJO, Ana Cristina. Cultura das Luzes em Portugal: temas e problemas. Lisboa, 2003.

ARENDT, Hannah. Man in the dark times. A Harvest book. Hardcourt, Brace \& World, Inc. New York,1968.

BARATA, Alexandre Mansur. Sociabilidade Ilustrada \& Independência no Brasil. Editora UFJF. Juiz de Fora, 2006.

BICALHO, Maria Fernanda Batista. Conquistas, Mercês e poder local: a nobreza da terra na América Portuguesa e a cultura política no Antigo Regime. In: Almanack Braziliense, $\mathrm{n}^{\circ} 2$, 2005.

BETHENCOURT, Francisco. Os Equilíbrios Sociais do Poder, In.: MATTOSO, José (dir.) História de Portugal: No Alvorecer da Modernidade. Lisboa: Editorial Estampa, 1993.

Francisco. A Inquisição. In: Yvette Kace Centeno (coord.), Portugal: mitos revisitados, Lisboa: Edições Salamandra, 1993.

Francisco. História das Inquisições: Portugal, Espanha e Itália, séculos XVI-XVIII. São Paulo: Companhia das Letras, 2000.

BLANCO MARTINEZ, Rogelio. La Ilustración em Europa y em España. Ensayo Ediciones Endymion. Madrid, 1999.

BOSCHI, Caio César. A Universidade de Coimbra e a formação intelectual das elites mineiras coloniais. In: Achegas à história de Minas Gerais. Porto, Universidade Portucalense Infante D. Henrique, 1994.

BURKE, Peter. A República das Letras europeia, 1500-2000. In.: Estudos Avançados 25 (72), 2011.

CÂNDIDO, Antônio. Apresentação. In: FRANCO, Francisco de Melo. Medicina Teológica (1794). Coleção Memória, $13^{\circ}$ volume. Ed. Giordano. São Paulo,1994.

CHARTIER, Roger. Origens Culturais da revolução francesa. Trad. George Schlesinger.- São Paulo: Ed. UNESP, 2009.

DARNTON, Robert. Boemia Literária e revolução. Tradução: Luís Carlos Borges. São Paulo. Companhia das Letras, 1987. 
ELIAS, Norbert. A sociedade de corte: investigação sobre a sociologia da realeza e da aristocracia de corte. Tradução: Pedro Süssekind. Prefácio: Roger Chartier. Rio de Janeiro, Editora Jorge Zahar. 2001

FURTADO, Júnia Ferreira. Sedição, heresia e rebelião nos trópicos: a biblioteca do naturalista José Vieira do Couto. In: DUTRA, Eliana de Freitas; MOLLIER, Jean-Yves (org.). Política, Nação e Edição; o lugar dos impressos na construção da vida política: Brasil, Europa e Américas nos séculos XVIII-XX. São Paulo: Anablume, 2006.

NEVES, Lúcia Bastos Pereira. Revolução: em busca de um conceito no Império LusoBrasileiro (1789-1822). In: JUNIOR, João Ferez. JASMIN, Marcelo (org.).História dos conceitos: diálogos transatlânticos. Rio de Janeiro, 2002

NOVINSKY, Anita. Estudantes brasileiros "afrancesados" na Universidade de Coimbra. A perseguição de Antônio de Morais e Silva. In: A Revolução Francesa e seu impacto na América Latina. COGGIOLA, Osvaldo (org.). Edusp, São Paulo. 1990.

MARCOCCI, Giuseppe e PAIVA, José Pedro. História da Inquisição portuguesa: 1536-1821. $1^{\mathrm{a}}$ edição. A Esfera dos Livros, editora. Lisboa, 2013.

MONCADA, Luís Cabral de. Um 'iluminista' português do século XVIII: Luís António Verney. In.: "Estudos de História do Direito". Volume III. Coimbra, 1950.

PAIVA, José Pedro. Revisitar o processo inquisitorial do padre António Vieira. In: Revista Lusitania Sacra. 23 (Janeiro-Junho 2011)151-168.

RAMOS, Luís A. de Oliveira. Sob o signo das 'Luzes'. Lisboa: Imprensa Nacional/ Casa da Moeda, 1988.

ROWLAND, Robert. Cristãos novos, marranos e judeus no espelho da Inquisição. In: Topoi, v. 11, n. 20, jan.-jun. 2010. Pp. 172-188.

SARAIVA, Antônio José. Inquisição e Cristãos-Novos. Histórias de Portugal (coleção). Editorial Estampa. Lisboa, 1994. $6^{\text {a }}$ edição.

SCHWARTZ, Stuart. Cada um na sua lei: tolerância religiosa e salvação no mundo atlântico ibérico. Tradução: Denise Bottman. EDUSC/Companhia das Letras. Bauru. 2009.

VAINFAS, Ronaldo - Moralidades Brasílicas: deleites sexuais e linguagem erótica na sociedade escravista- In: SOUZA, Laura de Mello e.(org.). História da Vida Privada no Brasil. São Paulo, Companhia das Letras, 1997.

VILlALTA, Luiz Carlos. A Censura, a circulação e a posse de romances na América Portuguesa (1722-1822). In: ABREU, Márcia de Azevedo, Márcia Azevedo Abreu; SCHAPOCHNICK, Nelson. (Org.). Cultura letrada no Brasil: objetos e práticas. 1 ed. Campinas; São Paulo: Mercado de Letras; Fapesp, 2005

Leituras Libertinas. In: Revista do Arquivo Público Mineiro. Ano 48, v. 1. Jan/Dez. 2012. Belo Horizonte. 
, As reformas pombalinas e a instrução. In: FONSECA, Thais Nívea de Lima e (Org.). 250 Anos das Reformas Pombalinas. Belo Horizonte: Autêntica/ FAPEMIG, 2011

, Montesquieu's Persian Letters and reading practices in the Luso-Brazilian World. In: PAQUETE, Gabriel. (Org.). Enlightened Reform in Southern Europe and its Atlantic Colonies, c. 1750-1830. Farnham: Ashgate, 2009

As Imagens, o Antigo Regime e a Revolução no Mundo Luso-Brasileiro. (CONFERERÊNCIA PROFERIDA NA SEMANA DE HISTÓRIA DA UFJF, EM JUIZ DE FORA, MG). 2010. (APRESENTAÇÃO DE TRABALHO/CONFERÊNCIA OU PALESTRA). Disponível em "Blogue de História Lusófona- Ano VI, Março 2011 $<$ http://www2.iict.pt/archive/doc/bHL_Ano_VI_04_-

_Luiz_Carlos_Villalta_As_imagens_e_o_controle_da_difusao_de_ideias_em_Portugal_no_ ocaso_do_Antigo_Regime.pdf> Acesso em 17/06/2013.

Reformismo ilustrado, Censura e Práticas de Leitura: os usos do livro na América Portuguesa. São Paulo: FFLCH-USP,1999 ( Tese de doutoramento em História), USP- 1999.

\section{FONTES}

Arquivos Nacionais da Torre do Tombo, Processo no 028/Cx. 1577/13638. Apresentação de Gonçalo Garcia.

ANTT, Processo n ${ }^{\circ}$ 028/13-336. Processo contra José Antônio da Silva.

ANTT, Processo $n^{\circ}$ 028/09275, Apresentação de Maria Madalena Salvada.

ANTT. Processo nº28/13977. Denúncias contra Francisco Luiz de Mariz Sarmento

ANTT, Processo número,13367, Culpas contra Manuel Galvão

ANTT. Processo n ${ }^{\circ}$ 028/06239. Processo contra Henrique de Jesus Maria.

ANTT. Processo n028/13977. Denúncias contra Francisco Luiz de Mariz Sarmento.

ANTT, Processo $n^{\circ}$ 028/09744. Processo de Pedro Manoel Bernes.

ANTT, Inquisição de Lisboa, Processo 028/01810- Processo contra Rodrigo Sodré Pereira.

SILVA, Antônio de Morais. Diccionario da lingua portugueza - volume 2. Disponível em: http://www.brasiliana.usp.br/en/dicionario/2/libertino, acessado no dia 21/05/2013. P. 221.

Paul Henri Thiry, Baron d'Holbach. System of Nature; or, the Laws of the Moral and Physical World (London, 1797), Vol. 1

CUNHA, Cardeal da. Regimento do Santo Officio da Inquisição dos Reinos de Portugal. Autor: Inquisidor Geral Cardeal da Cunha. Anno MCDDLXXIV. Organização: Manuel Gomes. Primeira edição fac-similada, Novembro/2000. Depósito Legal, nº 158 695/00.

ARTIGO ENVIADO EM: 22/12/2013

ACEITO PARA PUBLICAÇÃO EM: 28/04/2014 